Eur J Neurosci. Author manuscript; available in PMC 2015 February 17.

Published in final edited form as:

Eur J Neurosci. 2014 July ; 40(1): 2255-2263. doi:10.1111/ejn.12594.

\title{
Sustained $\mathrm{N}$-methyl-D-aspartate receptor hypofunction remodels the dopamine system and impairs phasic signaling
}

\author{
Mark J. Ferris ${ }^{1}$, Marija Milenkovic ${ }^{2}$, Shuai Liu ${ }^{3}$, Catharine A. Mielnik ${ }^{2}$, Pieter Beerepoot ${ }^{2}$, \\ Carrie E. John ${ }^{1}$, Rodrigo A. España ${ }^{1}$, Tatyana D. Sotnikova ${ }^{3}$, Raul R. Gainetdinov ${ }^{3,5,6}$, \\ Stephanie L. Borgland ${ }^{4}$, Sara R. Jones ${ }^{1}$, and Amy J. Ramsey ${ }^{2}$ \\ ${ }^{1}$ Department of Physiology and Pharmacology, Wake Forest School of Medicine, Winston-Salem, \\ NC, USA \\ 2Department of Pharmacology and Toxicology, University of Toronto, 1 King's College Circle, \\ Toronto, ON M5S 1A8, Canada \\ ${ }^{3}$ Department of Neuroscience and Brain Technologies, Istituto Italiano di Tecnologia, Genova, \\ Italy \\ ${ }^{4}$ Department of Anesthesiology, Pharmacology \& Therapeutics, University of British Colombia, \\ Vancouver, BC, Canada \\ ${ }^{5}$ Skolkovo Institute of Science and Technology, Moscow, Russia \\ ${ }^{6}$ Faculty of Biology and Soil Science, St. Petersburg State University, St. Petersburg, Russia
}

\begin{abstract}
Chronic $\mathrm{N}$-methyl-D-aspartate receptor (NMDAR) hypofunction has been proposed as a contributing factor to symptoms of schizophrenia. However, it is unclear how sustained NMDAR hypofunction throughout development affects other neurotransmitter systems that have been implicated in the disease. Dopamine neuron biochemistry and activity were examined to determine whether sustained NMDAR hypofunction causes a state of hyperdopaminergia. We report that a global, genetic reduction in NMDARs led to a remodeling of dopamine neurons, substantially affecting two key regulators of dopamine homeostasis, i.e. tyrosine hydroxylase and the dopamine transporter. In NR1 knockdown mice, dopamine synthesis and release were attenuated, and dopamine clearance was increased. Although these changes would have the effect of reducing dopamine transmission, we demonstrated that a state of hyperdopaminergia existed in these mice because dopamine $\mathrm{D}_{2}$ autoreceptors were desensitized. In support of this conclusion, NR1 knockdown dopamine neurons have higher tonic firing rates. Although the tonic firing rates are higher, phasic signaling is impaired, and dopamine overflow cannot be achieved with exogenous high-frequency stimulation that models phasic firing. Through the examination of several parameters of dopamine neurotransmission, we provide evidence that chronic NMDAR hypofunction leads to a state of elevated synaptic dopamine. Compensatory mechanisms to
\end{abstract}

Correspondence: Amy J Ramsey, as above. a.ramsey@utoronto.ca.

Conflict of interest statement

R.R.G. is supported in part by research awards from F. Hoffmann-La Roche Ltd (Basel, Switzerland) and Fondazione Compagnia di San Paolo (Torino, Italy). The remaining authors have no financial disclosures or conflicts of interest to report. 
attenuate hyperdopaminergia also impact the ability to generate dopamine surges through phasic firing.

\section{Keywords}

14-3-3; burst firing; mouse; NMDA; schizophrenia

\section{Introduction}

$\mathrm{N}$-methyl-D-aspartate receptor (NMDAR) antagonists, such as phencyclidine, ketamine, and dizocilpine, induce hallucinations and changes in perception as well as impairing performance on cognitive tasks and inducing social withdrawal (Javitt \& Zukin, 1991; Lahti et al., 1995; Newcomer et al., 1999; Lahti et al., 2001). The psychotomimetic effect of NMDAR antagonists has given rise to the compelling argument that NMDAR hypofunction is a feature of schizophrenia (Javitt \& Zukin, 1991; Coyle, 2006). However, schizophrenia probably involves impairment of neurotransmitter functions throughout development, and single administrations of antagonists do not model this feature of the disease. Indeed, anecdotal reports and studies in non-human primates suggest that chronic NMDAR antagonism more faithfully recapitulates the symptoms of schizophrenia than acute administration (Jentsch \& Roth, 1999). Even these studies do not, however, involve a sustained blockade of NMDARs throughout the lifespan.

It is vitally important to understand the effects of chronic NMDAR hypofunction if we are to accurately interpret human studies as evidence of an altered neurotransmitter system. For example, an observed postmortem change in dopamine (DA) receptor levels could indicate the cause of the disease, or it could be a secondary consequence of NMDAR hypofunction. Genetic mouse models can therefore provide critical information about the dynamic relationship between NMDAR function and DA biology. Because DA neuro-transmission is strongly implicated in schizophrenia (Angrist et al., 1971; Seeman et al., 1976; Snyder, 1976), the effect of NMDAR hypofunction on DA transmission has been a subject of much investigation. However, the majority of these studies have only examined the impact of acute NMDAR antagonists on DA neurons.

Such studies generally indicate an increase in striatal DA transmission with acute NMDAR antagonism. Indeed, it has been reported that the overall tonic firing rate of DA neurons is increased when NMDAR antagonists are delivered systemically (Pawlowski et al., 1990; Svensson, 2000). Interestingly, the effects of systemic antagonists on extracellular DA levels have been equivocal, pointing to the complexity of DA/glutamate interactions (Carlsson et al., 1999).

Importantly, although acute NMDAR antagonists appear to increase tonic firing rates as discussed above, they have the opposite effect on phasic (burst) firing when applied locally to DA neurons. The burst firing rate is reduced when NMDARs are blocked by local antagonists in midbrain regions (Sombers et al., 2009), or when they are selectively deleted in DA neurons (Zweifel et al., 2009). Conversely, when the agonist $N$-methyl-D-aspartate (NMDA) is applied locally to ventral tegmental area (VTA) neurons, burst firing increases as 
well as extracellular DA and DA transients in the nucleus accumbens (NAc) (Johnson et al., 1992; Avshalumov et al., 2003; Wanat et al., 2008). Thus, given the dual role of NMDARs in tonic and phasic firing of DA, it is unclear how sustained NMDAR hypofunction would ultimately affect DA transmission.

We hypothesized that the status of DA transmission would differ between sustained hypofunction of NMDAR signaling and acute pharmacological antagonism due to compensatory adaptations. Further, we hypothesized that any compensatory neurochemical changes that occur with sustained hypofunction would be informative for chronic disease states like schizophrenia where NMDAR function could be impaired. This hypothesis was tested using NR1 knockdown (NR1-KD) mice, which have a global reduction in NMDARs and NMDA-evoked current (Mohn et al., 1999; Jocoy et al., 2011). These mice were used to determine whether excessive DA neuro-transmission occurs with chronic deficiency of NMDARs.

\section{Materials and methods}

\section{Animals}

The NR1-KD mice were generated by targeted mutation of the Grin1 (GluN1) gene as described previously (Mohn et al., 1999; Ramsey et al., 2008). Experiments were performed on mice aged 12-15 weeks using sex-matched littermates. Animals were maintained in accordance with NIH guidelines for the welfare and treatment of experimental animals, and under the approval of the University of Toronto and Wake Forest University Biomedical Center Animal Care and Use Committees.

\section{Slice electrophysiology}

All of the electrophysiological recordings were performed in mice ranging from postnatal day 21-30. Mice were anesthetized with isoflurane and decapitated. Horizontal sections of the VTA $(250 \mu \mathrm{m})$ were prepared with a vibratome (Leica Microsystems, Nussloch, Germany). Slices were placed in a holding chamber and allowed to recover for at least $1 \mathrm{~h}$ before being placed in the recording chamber and superfused with bicarbonate-buffered solution (artificial cerebrospinal fluid) saturated with $95 \% \mathrm{O}_{2} / 5 \% \mathrm{CO}_{2}$ and containing (in $\mathrm{mM}$ ): $119 \mathrm{NaCl}, 2.5 \mathrm{KCl}, 1.0 \mathrm{NaH}_{2} \mathrm{PO}_{4}, 1.3 \mathrm{MgCl}_{2}, 2.5 \mathrm{CaCl}_{2}, 26.2 \mathrm{NaHCO}_{3}$ and 11 glucose (at $\left.32-34{ }^{\circ} \mathrm{C}\right)$. Picrotoxin $(100 \mu \mathrm{M})$ was added to block $\mathrm{GABA}_{\mathrm{A}}$ receptor-mediated inhibitory postsynaptic currents. Cells were visualized using infrared differential interference contrast video microscopy. Whole-cell current-clamp recordings were made using a Multiclamp 700A amplifier (Axon Instruments, Union City, CA, USA). Electrodes (2.8-4.0 M $\Omega$ ) contained: $140 \mathrm{mM}$ potassium D-gluconate, $5 \mathrm{mM} \mathrm{KCl}, 10 \mathrm{mM}$ HEPES, 0.2 mM EGTA, $2 \mathrm{mM} \mathrm{NaCl}, 2.5 \mathrm{mg} / \mathrm{mL}$ MgATP, $0.25 \mathrm{mg} / \mathrm{mL}$ guanosine triphosphate, and $0.2 \%$ Biocytin, pH 7.2-7.4, 275-285 mOsm. Data were acquired at $20 \mathrm{kHz}$ and filtered at 2 $\mathrm{kHz}$.

Dopamine neurons were identified by the presence of a hyperpolarizing cation current $\left(I_{h}\right)$, which is a good predictor of tyrosine hydroxylase $(\mathrm{TH})$-positive neurons in mice (Wanat et al., 2008). To examine the $I_{h}$, neurons were held at $-70 \mathrm{mV}$, and a series of voltage steps 
( $250 \mathrm{~ms}$, from -40 to $-130 \mathrm{mV}$ in $10-\mathrm{mV}$ steps) was applied. The $I_{h}$ was determined for the voltage step to $-130 \mathrm{mV}$. It was determined as the change in current between $\sim 30$ and 248 $\mathrm{ms}$ after the voltage step was applied. A subset of neurons was filled with biocytin $(0.2 \%)$ to confirm the presence of TH using methods described in Thompson \& Borgland (2013). To investigate VTA neuron excitability, neurons were held at $-60 \mathrm{mV}$, and depolarizing current steps ( $400 \mathrm{~ms}$, from 0 to $+350 \mathrm{mV}$ in $50-\mathrm{mV}$ steps) were applied. The slope of the number of spikes per depolarizing step was used as a measure of excitability.

\section{Fast-scan cyclic voltammetry}

Mice were anesthetized with isoflurane, decapitated and their brains rapidly removed and prepared as previously described (John \& Jones, 2007). Coronal slices (400 $\mu \mathrm{m})$ of the striatum were cut using a vibratome. Slices were maintained at $32{ }^{\circ} \mathrm{C}$ in oxygenated $(95 \%$ $\mathrm{O}_{2} / 5 \% \mathrm{CO}_{2}$ ) artificial cerebrospinal fluid as previously described (John \& Jones, 2007; Ferris et al., 2011).

The potential of a carbon-fiber microelectrode (Cahill et al., 1996) was linearly scanned from -400 to $1200 \mathrm{mV}$ and back to $-400 \mathrm{mV}$ vs. $\mathrm{Ag} / \mathrm{AgCl}$ (at $300 \mathrm{~V} / \mathrm{s}$ ), repeated every 100 $\mathrm{ms}$. DA release (identified by its characteristic voltammogram) was evoked every $5 \mathrm{~min}$ by a one-pulse stimulation (monophasic, $750 \mu \mathrm{A}, 4$-ms pulse width) from an adjacent bipolar stimulating electrode (Plastics One, Roanoke, VA, USA) placed on the surface of the slice, 100-200 $\mu \mathrm{m}$ away from the carbon-fiber microelectrode, positioned $75 \mu \mathrm{m}$ below the surface of the slice. The oxidation current was converted to a concentration by calibration with $3 \mu \mathrm{M}$ DA at the end of the experiment. Release is expressed in $\mu \mathrm{M}$ measured at the peak of the signal, whereas uptake was measured using the exponential time constant tau, which is the time required (in s) for the decaying signal to reach one-third of the peak height. All voltammetric data acquisition and modeling were performed using Demon Voltammetry and Analysis software (Yorgason et al., 2011).

Parameters for the multiple-pulse stimulation experiment were identical to the one-pulse studies except that five pulses were applied across increasing frequencies $(5,10,20,25$ and $100 \mathrm{~Hz}$ ) after one-pulse stimulation stabilized. These parameters were chosen to investigate the frequencies considered to represent both tonic (single pulse and five pulses at $<20 \mathrm{~Hz}$ ) and phasic (five pulses at $\geq 20 \mathrm{~Hz}$ ) burst firing of DA neurons (Rice \& Cragg, 2004; Zhang et al., 2009).

The DA release and uptake kinetics were assessed in wild-type (WT) mice in drug-free conditions in order to compare with NR1-KD mice, as well as in the presence of a 50- $\mu \mathrm{M}$ concentration of the NMDAR antagonist, (2R)-amino-5-phosphonovaleric acid (AP-5) (Sigma).

\section{In vivo tyrosine hydroxylase activity}

Mice were injected intraperitoneally with 3-hydroxybenzylhydrazine (Sigma) at a dose of $100 \mathrm{mg} / \mathrm{kg}$ in saline. At $60 \mathrm{~min}$ after injection, each mouse was killed by cervical dislocation and the striatum, hippocampus, and frontal cortex were rapidly dissected, weighed, and frozen in liquid nitrogen. Brain tissues were homogenized in $0.1 \mathrm{M}$ perchloric acid, and LDOPA levels were determined by high-performance liquid chromatography coupled with an 
electrochemical detector as described previously (Jones et al., 1999) ( $n=5$ animals per genotype, statistical analysis using Excel software and two-tailed t-test).

\section{Isolation of synaptic protein fractions}

The subcellular fractionation of synaptic membranes and associated proteins was performed as described previously (Cotman \& Taylor, 1972; Salahpour et al., 2008; Ramsey et al., 2011). For each sample, striatal tissue from three mice of the same genotype was pooled together and homogenized in a sucrose solution $(0.32 \mathrm{M}$ sucrose, $4 \mathrm{mM}$ Hepes, $\mathrm{pH}$ 8.0, with protease inhibitors). After nuclei were removed with centrifugation at $900 \mathrm{~g}$, the crude membranes were washed with the same sucrose solution and pelleted by centrifugation at 10 $000 \mathrm{~g}$. Hypotonic lysis was performed, and the resulting membranes were applied to a discontinuous sucrose gradient $(0.8,1.0$ and $1.2 \mathrm{M}$ sucrose, $4 \mathrm{mM}$ Hepes with protease inhibitors). Synaptic fractions were isolated by ultracentrifugation at $150000 \mathrm{~g}$ for $2 \mathrm{~h}$, and recovered at the interphase between 1.0 and $1.2 \mathrm{M}$ sucrose. This preparation has been shown to include both presynaptic and postsynaptic membranes and associated proteins, including presynaptic vesicles (Cotman \& Taylor, 1972).

\section{Western blot analysis}

Animals were killed by cervical dislocation and striatal tissue [including the caudate putamen $(\mathrm{CPu})$ and $\mathrm{NAc}]$ was rapidly dissected on ice and frozen in liquid nitrogen. Homogenates were resuspended in lysis buffer (60 mM Pipes, $25 \mathrm{mM}$ Hepes, $10 \mathrm{mM}$ EGTA, $2 \mathrm{mM} \mathrm{MgCl} 2,0.5 \%$ Triton-X, protease and phosphatase inhibitors). The protein concentration was determined by bicinchoninic acid protein assay (Pierce), and $20 \mu \mathrm{g}$ of protein extract was used for sodium dodecyl sulfate-polyacrylamide gel electrophoresis. The primary antibodies used were as follows: rat a-DA transporter (DAT) $(1: 1000$, Millipore), mouse a-TH ( $1: 1000$, Sigma), mouse a-14-3-3e (1:3000, Abcam), and mouse antiglyceraldehyde 3-phosphate dehydrogenase (a-GAPDH) (1:5000, Sigma). Immunoreactivity was detected with a LiCor Odyssey infrared imaging system and densitometry was measured using NIH ImageJ64 software. Statistical analysis was performed with GraphPad Prism using a two-tailed t-test.

\section{Results}

\section{Reduction in the electrically-evoked release of dopamine}

In our previous studies using NR1-KD mice, we found no significant changes in several global parameters of DA function. These measures included the striatal tissue content of DA and its metabolites, extracellular levels of DA measured by microdialysis, levels of the DAT measured using radioligand binding, and striatal levels of the postsynaptic $\mathrm{D}_{1}$ and $\mathrm{D}_{2} \mathrm{DA}$ receptors (Mohn et al., 1999; Ramsey et al., 2008). Despite the apparent normality of the DA system, these mice displayed altered behaviors consistent with models of psychosis, and several of these behaviors improved with antipsychotic drugs (Mohn et al., 1999; Duncan et al., 2006; Halene et al., 2009). Therefore, we hypothesized that alterations in DA neurotransmission might be observed in these mice using more dynamic, sub-second measurements of DA signaling rather than static measurements like radioligand binding. 
Subsecond DA release was measured using fast-scan cyclic voltammetry in brain slices paired with electrical stimulation of DA terminals in both the $\mathrm{CPu}$ and the core of the NAc. There was a substantial reduction in the amount of DA that was released by a single electrical pulse in NR1-KD mice, as demonstrated by the representative DA traces in Fig. $1 \mathrm{~A}$ and grouped data in Fig. 1B. In both regions, significant reductions in the single-pulseevoked DA peak height were observed in NR1-KD mice, with the effect being more prominent in the $\mathrm{CPu}\left(65 \%\right.$ reduction, $\left.t_{8}=1.91, P<0.001\right)$ than in the NAc core $(35 \%$ reduction, $t_{39}=1.91, P<0.05$ ) (Fig. $1 \mathrm{~A}$ and $\mathrm{B}$ ). AP-5 had no effect on DA release from WT animals and release remained significantly higher when AP-5 treatment in WT animals was compared with NR1-KD mice $\left(t_{19}=2.69, P<0.01\right)$.

\section{Reduction in dopamine synthesis through alterations in tyrosine hydroxylase levels and activity}

To understand the mechanism for the striking attenuation of DA release, we investigated the state of DA synthesis in the NR1-KD striatum. It has been shown that electrically-evoked DA release is more dependent on readily-releasable DA stores, which are particularly sensitive to DA synthesis, whereas extracellular DA levels as measured by microdialysis are more dependent on the function of the DA and vesicular transporters (Besson et al., 1969; Yavich, 1996; Yavich \& MacDonald, 2000). We hypothesized therefore that the reduction in electrically-evoked DA reflected a decrease in the activity of DA synthetic enzymes.

The activity of TH in vivo can be assessed by blocking aromatic L-amino acid decarboxylase activity with 3-hydroxybenzylhydrazine, and measuring the accumulation of L-DOPA, the product of TH activity (Jones et al., 1998). L-DOPA accumulation after 3hydroxybenzylhydrazine was significantly reduced in the striatal tissues (combining the $\mathrm{CPu}$ and NAc) of NR1-KD mice, indicating a $20 \%$ reduction in in vivo TH activity $\left(t_{9}=2.52, P=\right.$ 0.03) (Fig. 2A).

The in vivo activity of TH can be regulated by changes in protein levels, or by the phosphorylation of serine residues that control enzyme activity and stability (Pickel et al., 1981; Royo et al., 2005; Halskau et al., 2009). Phosphorylation and TH activity are regulated by the binding of 14-3-3e, which was originally named tyrosine mono-oxygenase activating protein, due to its requirement for in vitro assays for TH activity (Ichimura et al., 1987). $14-3-3 \varepsilon$ binds to phoshorylated TH to markedly increase TH activity (Halskau et al., 2009).

To investigate the reduction in TH activity, striatal protein levels were determined by western blot. Total levels of the enzyme showed a trend decrease $\left(t_{4}=1.55, P=0.19\right)$ (Fig. $2 \mathrm{~B}$ and $\mathrm{C}$ ). However, we also measured the levels of TH protein from synaptic fractions, which were prepared by sucrose density gradient. Our previous studies had uncovered a synapse-specific reduction in 14-3-3e in NR1-KD striatum (Ramsey et al., 2011), and we reasoned that synaptic reduction in 14-3-3e might also affect the synaptic levels of TH due to its known role in regulating TH stability. Indeed, in synaptic fractions of NR1-KD striatum, TH levels were reduced by $65 \%\left(t_{4}=3.23, P=0.03\right)$ (Fig. $2 \mathrm{~A}$ and B). This was consistent with a similar $60 \%$ reduction in $14-3-3 \varepsilon$ from the same protein extracts $\left(t_{4}=4.39\right.$, $P=0.01$ ) (Fig. 2B and C). Interestingly, both TH and 14-3-3 $\varepsilon$ are known to exist in both cytoplasmic and membrane-associated fractions (Halskau et al., 2009; Cartier et al., 2010), 
and significant reductions are seen in the striatal synaptic membrane fractions of NR1-KD mice.

\section{Increased clearance rate of dopamine through increased dopamine transporter levels}

In addition to the release of DA, the activity of the DAT represents a key point of regulation for the homeostatic control of DA signaling and extracellular levels of DA. To evaluate the activity of the DAT in NR1-KD mice, the clearance rate of electrically-evoked DA was measured using fast-scan cyclic voltammetry. The clearance rate is characterized by the rate constant, tau, which is the time required for the DA levels to decay to one-third of the maximum peak height (Yorgason et al., 2011).

Representative traces in Fig. 3A show an increase in the functional activity of DATs in NR1$\mathrm{KD}$ mice, as indicated by the faster clearance rate and smaller tau values. Group data indicated a main effect of genotype in both the NAc and CPu (Fig. 3B). Specifically, clearance times were reduced by $35 \%$ in both the NAc core (WT tau, $0.67 \pm 0.06 \mathrm{~s}$; NR1$\mathrm{KD}$ tau, $0.46 \pm 0.02 \mathrm{~s} ; t_{38}=2.51, P<0.01$ ) and CPu (WT tau, $0.53 \pm 0.01 \mathrm{~s} ; \mathrm{NR} 1-\mathrm{KD}$ tau, $\left.0.42 \pm 0.01 \mathrm{~s} ; t_{5}=6.61, P<0.001\right)$. AP-5 had no effect on DA uptake rates in WT animals and tau remained significantly higher when AP-5 treatment in WT animals was compared with NR1-KD mice $\left(t_{21}=5.76, P<0.0001\right)$. For consistency with other measures, $1 /$ tau is plotted on the y-axis of Fig. 3B such that the increase in uptake rate is depicted as an increase in $1 /$ tau.

Increased DAT activity could reflect an increase in either the trafficking of DAT to the synaptic plasma membrane or an enhancement in the intrinsic activity of the transporter. To investigate the possibility of increased transporter levels in perisynaptic plasma membranes, we measured the DAT protein levels from the total striatum and from striatal synaptic fractions in NR1-KD mice and WT littermates. Whereas the total levels of DAT were unchanged in the NR1-KD striatum, perisynaptic levels of DAT protein were increased by $45 \%\left(t_{10}=2.15, P=0.05\right)$ (Fig. 3C). Thus, although the total amounts of DAT were not changed in NR1-KD mice as measured by radioligand binding (Ramsey et al., 2008) and by western blot (Fig. 3C), the amount of DAT that was localized in synaptic membrane was increased, and DAT activity was also increased.

\section{$\mathrm{N}$-methyl-D-aspartate receptor hypofunction produces subsensitive dopamine autoreceptors}

Activation of autoreceptors at or near the terminal causes a decrease in the vesicular release of DA through hyperpolarized membrane potentials and decreased release probability (Groves et al., 1975; Lacey et al., 1987; Cragg \& Greenfield, 1997; Maina \& Mathews, 2010). In cases of sustained hyperdopaminergia, however, the $D_{2}$ autoreceptor becomes desensitized and is less responsive to the agonist (Jones et al., 1999). Thus, $D_{2}$ autoreceptor function can serve as an indicator of sustained, excessive synaptic DA.

To assess $\mathrm{D}_{2} \mathrm{DA}$ autoreceptor function in NR1-KD mice, fast-scan cyclic voltammetry was performed in striatal slices with quinpirole $(1 \mathrm{nM}-1 \mu \mathrm{M})$ and sulpiride $(2 \mu \mathrm{M})$ application. $\mathrm{D}_{2}$ autoreceptors were found to be less sensitive to the release-decreasing effects of the $\mathrm{D}_{2}$ agonist quinpirole in NR1-KD mice in both the NAc and CPu (Fig. 4A, left and right panel, 
respectively). In the NAc, there was a main effect of both quinpirole concentration $\left(F_{6,90}=64.57, P<0.001\right)$ and genotype $\left(F_{1,90}=26.25, P<0.001\right)$ with Bonferroni comparisons indicating significant differences at concentrations of $1-100 \mathrm{nM}(P<0.05)$. AP-5 had no effect on the ability of quinpirole to inhibit DA release from WT animals and quinpirole remained significantly more potent when compared with NR1-KD mice. Similarly, in the $\mathrm{CPu}$, a two-way ANOVA showed that there was a main effect of both quinpirole concentration $\left(F_{5,52}=19.52, P<0.001\right)$ and genotype $\left(F_{1,52}=19.24, P<0.001\right)$, with Bonferroni comparisons indicating significant differences at doses of 30 and $100 \mathrm{nM}(P$ $<0.05)$.

In addition to subsensitivity to the effects of the agonist quinpirole, stimulated release in NR1-KD slices was less responsive to a $\mathrm{D}_{2}$ antagonist, as indicated by a main effect of genotype following application of $2 \mu \mathrm{M}$ sulpiride. Specifically, sulpiride increased the stimulated DA release to a greater extent in WT mice than in NR1-KD mice, indicative of greater disinhibition of electrically-stimulated DA release in WT animals (Fig. 4B). Hence, $\mathrm{D}_{2}$-type autoreceptors were reduced in number or were uncoupled in their response to ligands, similar to an effect that has been observed in situations of chronically-elevated synaptic DA (Jones et al., 1999), and indicative of a hyperdopaminergic state in NR1-KD mice.

\section{Increased tonic firing rate and excitability of dopamine neurons}

One possible way of explaining this indication of increased DA neurotransmission in NR1$\mathrm{KD}$ mice is through an increase in the tonic firing rate of DA neurons. Indeed, it has been reported that acute, systemic NMDAR antagonism causes an increase in the firing rate of DA neurons (Pawlowski et al., 1990; Svensson, 2000). We questioned whether this would be true in a chronic, genetic model of impaired NMDAR function. We found that DA neurons do spontaneously fire at a significantly higher rate in NR1-KD slice preparations (Fig. 5A and $\left.\mathrm{B}, t_{15}=2.0, P<0.05\right)$. We next examined the intrinsic excitability of DA neurons from NR1-KD or WT mice as measured by the number of spikes elicited by depolarizing current steps. Neurons were held at $-60 \mathrm{mV}$, and depolarizing current steps ( $400 \mathrm{~ms}$, from 0 to +350 $\mathrm{mV}$ in 50-mV steps) were applied. Excitability was measured by determining the slope of the line given by the number of spikes fired at each depolarizing step. DA neurons of NR1KD mice spiked more often over the depolarizing steps than neurons from WT mice with slopes of $2.2 \pm 0.4$ and $1.0 \pm 0.1 \mathrm{pA}$, respectively, indicating increased excitability (Fig. 5C and $\left.\mathrm{D}, t_{18}=2.6, P<0.05\right)$.

\section{Reduced burst firing and inability to augment dopamine overflow in burst fire modeling}

Previous studies have demonstrated that NMDARs positively regulate burst firing (Johnson et al., 1992; Hopf et al., 2007; Sombers et al., 2009; Zweifel et al., 2009; Cacciapaglia et al., 2011). Many of these studies used local, acute application of NMDAR agonists and antagonists. We sought to determine whether this was still true in a chronic model of global NMDAR hypofunction. We applied NMDA to midbrain slices from WT or NR1-KD mice and recorded changes in firing of DA neurons. NMDA-evoked burst firing was observed in $50 \%$ of DA neurons from WT mice. In contrast, only one of eight of DA neurons from NR1KD mice burst fired (Fig. 6A and B). These results suggest that the probability of burst firing 
is decreased with reduced levels of NMDARs, in line with observations made using pharmacological manipulations.

Given the robust alterations in presynaptic DA systems in NR1-KD mice, including blunted DA release to single-pulse electrical stimulation (Fig. 1), we further investigated whether blunted DA responses would be present during multiple-pulse stimulations that correspond to phasic firing of DA neurons (five pulses at $\geq 20 \mathrm{~Hz}$ ) (Rice \& Cragg, 2004; Zhang et al., 2009). In mice lacking NR1 only in DA neurons, phasic DA release was shown to be blunted during a Pavlovian conditioning paradigm (Parker et al., 2010). However, it is unclear whether those effects were due to alterations in DA release or to differences in the activity of DA neurons. We tested DA release using exogenously applied stimulation in brain slices. This provides an ideal opportunity to explore whether DA release is intact when identical phasic stimulations are applied to both groups.

Five pulses of electrical stimulation were applied at frequencies ranging from 5 to $100 \mathrm{~Hz}$, and the amount of DA overflow was compared with that elicited by a single pulse of stimulation. Representative DA traces from WT mice in drug-free conditions and in the presence of AP-5 showed increasing DA release across increasing stimulation frequencies, whereas phasic bursts produced almost no differences in DA release across frequencies in NR1-KD mice (Fig. 5C). Grouped data indicated a main effect of genotype $\left(F_{2,68}=27.44, P\right.$ $<0.0001)$ and a Frequency $\times$ Genotype Interaction $\left(F_{8,68}=6.49, P<0.01\right.$; Fig. 6D). AP-5 had no effect on the ability of multiple pulses across all frequencies to augment DA release from WT animals, and DA release in the presence of AP-5 remained significantly higher at every frequency when compared with NR1-KD mice. These results indicate that NR1-KD mice do not produce DA surges during burst firing-like activity.

\section{Discussion}

In previous studies, we generated a mouse line with reduced levels of NMDARs due to a hypomorphic mutation of the essential NR1 subunit, encoded by the Grin1 gene (Mohn et al., 1999). They represent a model of NMDAR hypofunction not only because NMDAR levels are reduced to $10 \%$ of WT in these mice, but also because electrophysiological analyses indicate substantial reductions in NMDA current (Jocoy et al., 2011). Like mice treated acutely with NMDAR antagonists, they display increased locomotor activity, decreased sociability, impaired prepulse inhibition of acoustic startle, and impaired working memory (Duncan et al., 2004, 2006; Ramsey et al., 2008; Dzirasa et al., 2009; Ramsey et al., 2011). In addition, NR1-KD mice have an increased locomotor response to amphetamine (Ramsey et al., 2008).

Using electrochemical and electrophysiological methods to measure functional activity, we demonstrate that NR1-KD DA neurons undergo profound changes in their firing patterns and in several points of homeostatic regulation. Notably, alterations of dopaminergic function were not previously detected by static measures (radioligand binding, tissue content, and microdialysis), and the full impact of NMDAR hypofunction could only be assessed through the combination of static and rapid measures of DA signaling. These collective observations in the NR1-KD mouse emphasize the difficulty in interpreting only one or two clinical 
indices of the DA system. This is particularly important for the interpretation of postmortem studies of the schizophrenic brain, and in fact a hyperdopaminergic state may not always be detected through measurement of DA receptor levels.

At the biochemical level, alterations in TH and DAT could only be detected by performing subcellular fractionation and measuring protein levels in the synaptic membrane fraction. As DAT and TH are only present in DA neuron axons and terminals, the total protein content in the striatum is reflective of the levels of these proteins at the terminal. The observation that TH and DAT levels were only significantly altered in the synaptic fractions of NR1-KD mice suggests that there are cytosolic and membrane-associated pools. Increased DAT trafficking to the plasma membrane probably explains the increase in the clearance rate of DA, and reduced synaptic TH could explain the decrease in DA synthesis and even DA release. Several studies have demonstrated that TH exists in association with synaptic membranes (Pickel et al., 1981; Halskau et al., 2009; Cartier et al., 2010), but it is not clear to what extent this pool of TH contributes to the total levels of DA synthesis or whether it has a unique biological role. Perhaps the 'readily-releasable' pool of DA that is accessed by electrical stimulation may be more heavily influenced by membrane-associated TH activity, as has been proposed by Yavich \& MacDonald (2000).

Importantly, our results show that the neurochemical changes in synthesis, release, and uptake observed in the NR1-KD mice would all have the effect of dampening DA transmission. These are probably secondary to other changes that increase DA transmission, including higher tonic firing rate and less sensitive autoreceptors. As higher tonic firing is seen with acute NMDAR antagonism, this may be the trigger for other compensatory adaptations to the DA system. Importantly, acute NMDAR blockade did not cause changes in DA release, reuptake, or autoreceptor function, supporting the notion that the DA system is remodeled as a consequence of sustained, rather than acute, NMDAR hypofunction. We propose that increased DAT activity and DA clearance reflect a compensatory mechanism to keep extracellular levels of DA normalized in the face of high synaptic DA levels. These compensations may not fully normalize DA transmission, however, as demonstrated by the hyperactivity of NR1-KD mice that can be attenuated by DA receptor antagonists (Mohn et al., 1999; Ramsey et al., 2008).

The observed increase in tonic firing is consistent with the notion that NR1-KD DA neurons are disinhibited, although this was not directly tested with our experimental slice conditions. Our findings are, however, in line with the observation that acutely administered systemic NMDAR antagonists increase tonic firing rates of DA neurons (Pawlowski et al., 1990). Similarly, NMDAR antagonists affect cortical neuron activity by increasing tonic spiking events and reducing burst firing events (Jackson et al., 2004). Previous electrophysiological studies of NR1-KD mice have demonstrated higher firing rates of neuron populations in the hippocampus, frontal cortex, and striatum (Dzirasa et al., 2009; Jocoy et al., 2011). One potential explanation for increased spontaneous firing rates is that projection neurons are disinhibited. As some inhibitory inter-neurons rely heavily on NMDAR current for the generation of excitatory postsynaptic potentials (Grunze et al., 1996; Lei \& McB-ain, 2002; Maccaferri \& Dingledine, 2002), it has been suggested that these neurons may be more 
affected by reductions in NMDAR activity (Lisman et al., 2008), leading to a general state of projection neuron disinhibition.

Although DA neurons may be in a state of disinhibition, there is also evidence of increased intrinsic excitability in neurons of NR1-KD mice. In dopaminoceptive medium spiny neurons of these mutant mice, the AMPA receptor current is substantially increased in both slice and dissociated neuron preparations (Jocoy et al., 2011). Furthermore, in two other mouse models where NMDARs were selectively deleted in DA neurons, two groups report an increased AMPA receptor current (Engblom et al., 2008; Zweifel et al., 2008). It is of note that one group reported normal tonic firing rates (Zweifel et al., 2009), and the other reported increased tonic firing (Engblom et al., 2008). Thus, the finding that NR1-KD DA neurons have higher tonic firing could be due to both disinhibition and to alterations in the intrinsic excitability of DA neurons.

Although NR1-KD DA neurons have an increased tonic firing rate, their ability to release DA is impaired. Again, this is probably a compensatory mechanism in response to sustained NMDAR hypofunction, as acute NMDAR antagonists do not reduce the levels of electrically-evoked DA in slices (Avshalumov et al., 2003; Zhang \& Sulzer, 2003). As with these published studies, we did not observe a change in DA release in the presence of the acute NMDAR antagonist AP-5. It seems likely that the compensations that reduce electrically-evoked DA release are also to blame for the reduced ability to elevate DA with stimulations that model burst firing. Although it has previously been shown that NMDARs on DA neuron cell bodies are required for endogenously-generated burst firing events (Zweifel et al., 2009), our studies show that burst firing-related synaptic DA increases are impaired in states of chronic NMDAR hypofunction for two reasons. First, DA neurons would exhibit less burst firing, and second, DA neurons have several adaptive changes to dampen DA release and signaling during a burst firing event. Impressively, even presynaptic electrical stimulation to elicit DA surges, which bypasses the need for glutamate innervation, was largely ineffective in NR1-KD slices. Therefore, NR1-KD mice have a reduced ability to generate the DA surges that normally encode the physical salience, prediction value, or rewarding value of environmental stimuli (Fiorillo et al., 2003; Day et al., 2007; Roitman et al., 2008; Schultz, 2010).

The behavioral significance of this is still unclear, particularly as some aspects of learning and Pavlovian conditioning remain intact when NMDARs are deleted from DA neurons (Zweifel et al., 2008; Parker et al., 2010). In that cell-selective knockout, only phasic firing is affected, and tonic firing of DA neurons is unchanged (Zweifel et al., 2009). Despite attenuation in the amount of DA released by phasic firing, the cell-selective knockout mice were still able to learn an operant task (Parker et al., 2010). An important difference between the global knockdown and the DA-selective knockout may in fact be the increased tonic firing that is only detected in the NR1-KD mice. We propose that some of the behavioral phenotypes of NR1-KD mice may be due in part to a lack in the dynamic range in DA signaling. Future studies with cell- or region-selective restoration of NMDARs will help to dissect the contribution of altered DA signaling to the several behavioral phenotypes of NR1-KD mice. 
Our studies support the hypothesis that NMDAR hypofunction causes increased DA neuron firing and synaptically elevated DA, but this does not lead strictly to the same state of hyperdopaminergia as acute NMDAR antagonism. Instead, in chronic states of NMDAR deficiency, DA neurons engage presynaptic adaptations to dampen and normalize extracellular DA tone. One consequence of these adaptations is the inability to generate DA surges, which, in concert with high tonic firing rates, may reduce the dynamic range of DA signaling and ultimately contribute to psychosis-like behaviors.

\section{Acknowledgments}

The authors would like to thank Dr Marc Caron for helpful discussion and comments, Dr Ali Salahpour for critical reading of the manuscript, and Wendy Horsfall for mouse colony maintenance and technical support. This work was supported by Operating Grants from CIHR (A.J.R. and S.L.B.), CIHR New Investigator Award (S.L.B.), NARSAD Young Investigator Award (A.J.R.), and NIH (P50 DA006634, RO1 DA021345, R21 AA013900 and P01 AA17506) (S.R.J.). M.J.F. was supported by NIH (T32DA007246 and K99DA031791). R.R.G. was supported by an internal SPBSU grant 1.38.201.2014. C.A.M. was a recipient of a CIHR Master's fellowship.

\section{Abbreviations}

$\begin{array}{ll}\text { AP-5 } & \text { (2R)-amino-5-phosphonovaleric acid } \\ \text { CPu } & \text { caudate putamen } \\ \text { DA } & \text { dopamine } \\ \text { DAT } & \text { dopamine transporter } \\ \text { NAc } & \text { nucleus accumbens } \\ \text { NMDA } & N \text {-methyl-D-aspartate } \\ \text { NMDAR } & N \text {-methyl-D-aspartate receptor } \\ \text { NR1-KD } & \text { NR1 knockdown } \\ \text { TH } & \text { tyrosine hydroxylase } \\ \text { WT } & \text { wild-type }\end{array}$

\section{References}

Angrist BM, Shopsin B, Gershon S. Comparative psychotomimetic effects of stereoisomers of amphetamine. Nature. 1971; 234:152-153. [PubMed: 4942678]

Avshalumov MV, Chen BT, Marshall SP, Pena DM, Rice ME. Glutamate-dependent inhibition of dopamine release in striatum is mediated by a new diffusible messenger, $\mathrm{H}_{2} \mathrm{O}_{2}$. J Neurosci. 2003; 23:2744-2750. [PubMed: 12684460]

Besson MJ, Cheramy A, Glowinski J. Effects of amphetamine and desmethylimipramine on amines synthesis and release in central cate-cholamine-containing neurons. Eur J Pharmacol. 1969; 7:111114. [PubMed: 5821798]

Cacciapaglia F, Wightman RM, Carelli RM. Rapid dopamine signaling differentially modulates distinct microcircuits within the nucleus accumbens during sucrose-directed behavior. J Neurosci. 2011; 31:13860-13869. [PubMed: 21957248] 
Cahill PS, Walker QD, Finnegan JM, Mickelson GE, Travis ER, Wightman RM. Microelectrodes for the measurement of catecholamines in biological systems. Anal Chem. 1996; 68:3180-3186. [PubMed: 8797378]

Carlsson A, Waters N, Carlsson ML. Neurotransmitter interactions in schizophrenia - therapeutic implications. Biol Psychiat. 1999; 46:1388-1395. [PubMed: 10578453]

Cartier EA, Parra LA, Baust TB, Quiroz M, Salazar G, Faundez V, Egana L, Torres GE. A biochemical and functional protein complex involving dopamine synthesis and transport into synaptic vesicles. $\mathrm{J}$ Biol Chem. 2010; 285:1957-1966. [PubMed: 19903816]

Cotman CW, Taylor D. Isolation and structural studies on synaptic complexes from rat brain. J Cell Biol. 1972; 55:696-711. [PubMed: 4656707]

Coyle JT. Substance use disorders and Schizophrenia: a question of shared glutamatergic mechanisms. Neurotox Res. 2006; 10:221-233. [PubMed: 17197372]

Cragg SJ, Greenfield SA. Differential autoreceptor control of so-matodendritic and axon terminal dopamine release in substantia nigra, ventral tegmental area, and striatum. J Neurosci. 1997; 17:5738-5746. [PubMed: 9221772]

Day JJ, Roitman MF, Wightman RM, Carelli RM. Associative learning mediates dynamic shifts in dopamine signaling in the nucleus accumbens. Nat Neurosci. 2007; 10:1020-1028. [PubMed: 17603481]

Duncan GE, Moy SS, Perez A, Eddy DM, Zinzow WM, Lieberman JA, Snouwaert JN, Koller BH. Deficits in sensorimotor gating and tests of social behavior in a genetic model of reduced NMDA receptor function. Behav Brain Res. 2004; 153:507-519. [PubMed: 15265649]

Duncan GE, Moy SS, Lieberman JA, Koller BH. Effects of haloperidol, clozapine, and quetiapine on sensorimotor gating in a genetic model of reduced NMDA receptor function. Psychopharmacology. 2006; 184:190-200. [PubMed: 16362405]

Dzirasa K, Ramsey AJ, Takahashi DY, Stapleton J, Potes JM, Williams JK, Gainetdinov RR, Sameshima K, Caron MG, Nicolelis MA. Hyperdopaminergia and NMDA receptor hypofunction disrupt neural phase signaling. J Neurosci. 2009; 29:8215-8224. [PubMed: 19553461]

Engblom D, Bilbao A, Sanchis-Segura C, Dahan L, Perreau-Lenz S, Balland B, Parkitna JR, Lujan R, Halbout B, Mameli M, Parlato R, Sprengel R, Luscher C, Schutz G, Spanagel R. Glutamate receptors on dopamine neurons control the persistence of cocaine seeking. Neuron. 2008; 59:497508. [PubMed: 18701074]

Ferris MJ, Mateo Y, Roberts DC, Jones SR. Cocaine-insensitive dopamine transporters with intact substrate transport produced by self-administration. Biol Psychiat. 2011; 69:201-207. [PubMed: 20801429]

Fiorillo CD, Tobler PN, Schultz W. Discrete coding of reward probability and uncertainty by dopamine neurons. Science. 2003; 299:1898-1902. [PubMed: 12649484]

Groves PM, Wilson CJ, Young SJ, Rebec GV. Self-inhibition by dopaminergic neurons. Science. 1975; 190:522-528. [PubMed: 242074]

Grunze HC, Rainnie DG, Hasselmo ME, Barkai E, Hearn EF, Mc-Carley RW, Greene RW. NMDAdependent modulation of CA1 local circuit inhibition. J Neurosci. 1996; 16:2034-2043. [PubMed: 8604048]

Halene TB, Ehrlichman RS, Liang Y, Christian EP, Jonak GJ, Gur TL, Blendy JA, Dow HC, Brodkin ES, Schneider F, Gur RC, Siegel SJ. Assessment of NMDA receptor NR1 subunit hypofunction in mice as a model for schizophrenia. Genes Brain Behav. 2009; 8:661-675. [PubMed: 19563516]

Halskau O Jr, Ying M, Baumann A, Kleppe R, Rodriguez-Larrea D, Almas B, Haavik J, Martinez A. Three-way interaction between 14-3-3 proteins, the N-terminal region of tyrosine hydroxylase, and negatively charged membranes. J Biol Chem. 2009; 284:32758-32769. [PubMed: 19801645]

Hopf FW, Martin M, Chen BT, Bowers MS, Mohamedi MM, Bonci A. Withdrawal from intermittent ethanol exposure increases probability of burst firing in VTA neurons in vitro. J Neurophysiol. 2007; 98:2297-2310. [PubMed: 17699688]

Ichimura T, Isobe T, Okuyama T, Yamauchi T, Fujisawa H. Brain 14-3-3 protein is an activator protein that activates tryptophan 5-monooxygenase and tyrosine 3-monooxygenase in the presence of Ca2+, calmodulin-dependent protein kinase II. FEBS Lett. 1987; 219:79-82. [PubMed: 2885229] 
Jackson ME, Homayoun H, Moghaddam B. NMDA receptor hypofunction produces concomitant firing rate potentiation and burst activity reduction in the prefrontal cortex. Proc Natl Acad Sci USA. 2004; 101:8467-8472. [PubMed: 15159546]

Javitt DC, Zukin SR. Recent advances in the phencyclidine model of schizophrenia. Am J Psychiat. 1991; 148:1301-1308. [PubMed: 1654746]

Jentsch JD, Roth RH. The neuropsychopharmacology of phencyclidine: from NMDA receptor hypofunction to the dopamine hypothesis of schizophrenia. Neuropsychopharmacology. 1999; 20:201-225. [PubMed: 10063482]

Jocoy EL, Andre VM, Cummings DM, Rao SP, Wu N, Ramsey AJ, Caron MG, Cepeda C, Levine MS. Dissecting the contribution of individual receptor subunits to the enhancement of N-methyl-daspartate currents by dopamine D1 receptor activation in striatum. Front Syst Neurosci. 2011; 5:28. [PubMed: 21617735]

John, CE., Jones, SR. Fast Scan Cyclic Voltammetry of Dopamine and Serotonin in Mouse Brain Slices. In: Michael, AC., Borland, LM., editors. Electrochemical Methods for Neuroscience. CRC Press; Boca Raton, FL: 2007. p. 49-62.

Johnson SW, Seutin V, North RA. Burst firing in dopamine neurons induced by N-methyl-D-aspartate: role of electrogenic sodium pump. Science. 1992; 258:665-667. [PubMed: 1329209]

Jones SR, Gainetdinov RR, Jaber M, Giros B, Wightman RM, Caron MG. Profound neuronal plasticity in response to inactivation of the dopamine transporter. Proc Natl Acad Sci USA. 1998; 95:40294034. [PubMed: 9520487]

Lacey MG, Mercuri NB, North RA. Dopamine acts on D2 receptors to increase potassium conductance in neurones of the rat substantia nigra zona compacta. J Physiol. 1987; 392:397-416. [PubMed: 2451725]

Lahti AC, Koffel B, LaPorte D, Tamminga CA. Subanesthetic doses of ketamine stimulate psychosis in schizophrenia. Neuropsychopharmacology. 1995; 13:9-19. [PubMed: 8526975]

Lahti AC, Weiler MA, Tamara Michaelidis BA, Parwani A, Tamminga CA. Effects of ketamine in normal and schizophrenic volunteers. Neuropsychopharmacology. 2001; 25:455-467. [PubMed: 11557159]

Lei S, McBain CJ. Distinct NMDA receptors provide differential modes of transmission at mossy fiber-interneuron synapses. Neuron. 2002; 33:921-933. [PubMed: 11906698]

Lisman JE, Coyle JT, Green RW, Javitt DC, Benes FM, Heckers S, Grace AA. Circuit-based framework for understanding neurotransmitter and risk gene interactions in schizophrenia. Trends Neurosci. 2008; 31:234-242. [PubMed: 18395805]

Maccaferri G, Dingledine R. Control of feedforward dendritic inhibition by NMDA receptordependent spike timing in hippocampal interneurons. J Neurosci. 2002; 22:5462-5472. [PubMed: 12097498]

Maina FK, Mathews TA. A functional fast scan cyclic voltammetry assay to characterize dopamine D2 and D3 autoreceptors in the mouse striatum. ACS Chem Neurosci. 2010; 1:450-462. [PubMed: 20567609]

Mohn AR, Gainetdinov RR, Caron MG, Koller BH. Mice with reduced NMDA receptor expression display behaviors related to schizophrenia. Cell. 1999; 98:427-436. [PubMed: 10481908]

Newcomer JW, Farber NB, Jevtovic-Todorovic V, Selke G, Melson AK, Hershey T, Craft S, Olney JW. Ketamine-induced NMDA receptor hypofunction as a model of memory impairment and psychosis. Neuropsychopharmacology. 1999; 20:106-118. [PubMed: 9885791]

Parker JG, Zweifel LS, Clark JJ, Evans SB, Phillips PE, Palmiter RD. Absence of NMDA receptors in dopamine neurons attenuates dopamine release but not conditioned approach during Pavlovian conditioning. Proc Natl Acad Sci USA. 2010; 107:13491-13496. [PubMed: 20616081]

Pawlowski L, Mathe JM, Svensson TH. Phencyclidine activates rat A10 dopamine neurons but reduces burst activity and causes regularization of firing. Acta Physiol Scand. 1990; 139:529-530. [PubMed: 2239353]

Pickel VM, Beckley SC, Joh TH, Reis DJ. Ultrastructural immunocytochemical localization of tyrosine hydroxylase in the neostriatum. Brain Res. 1981; 225:373-385. [PubMed: 6118197] 
Ramsey AJ, Laakso A, Cyr M, Sotnikova TD, Salahpour A, Medvedev IO, Dykstra LA, Gainetdinov RR, Caron MG. Genetic NMDA receptor deficiency disrupts acute and chronic effects of cocaine but not amphetamine. Neuropsychopharmacology. 2008; 33:2701-2714. [PubMed: 18185498]

Ramsey AJ, Milenkovic M, Oliveira AF, Escobedo-Lozoya Y, Seshadri S, Salahpour A, Sawa A, Yasuda R, Caron MG. Impaired NMDA receptor transmission alters striatal synapses and DISC1 protein in an age-dependent manner. Proc Natl Acad Sci USA. 2011; 108:5795-5800. [PubMed: 21436042]

Rice ME, Cragg SJ. Nicotine amplifies reward-related dopamine signals in striatum. Nat Neurosci. 2004; 7:583-584. [PubMed: 15146188]

Roitman MF, Wheeler RA, Wightman RM, Carelli RM. Real-time chemical responses in the nucleus accumbens differentiate rewarding and aversive stimuli. Nat Neurosci. 2008; 11:1376-1377. [PubMed: 18978779]

Royo M, Fitzpatrick PF, Daubner SC. Mutation of regulatory serines of rat tyrosine hydroxylase to glutamate: effects on enzyme stability and activity. Arch Biochem Biophys. 2005; 434:266-274. [PubMed: 15639226]

Salahpour A, Ramsey AJ, Medvedev IO, Kile B, Sotnikova TD, Holmstrand E, Ghisi V, Nicholls PJ, Wong L, Murphy K, Sesack SR, Wightman RM, Gainetdinov RR, Caron MG. Increased amphetamine-induced hyperactivity and reward in mice overexpressing the dopamine transporter. Proc Natl Acad Sci USA. 2008; 105:4405-4410. [PubMed: 18347339]

Schultz W. Multiple functions of dopamine neurons. F1000. Biol Rep. 2010; :2. Epub ahead of print. doi: 10.3410/B2-2

Seeman P, Lee T, Chau-Wong M, Wong K. Antipsychotic drug doses and neuroleptic/dopamine receptors. Nature. 1976; 261:717-719. [PubMed: 945467]

Snyder SH. The dopamine hypothesis of schizophrenia: focus on the dopamine receptor. Am J Psychiat. 1976; 133:197-202. [PubMed: 1251927]

Sombers LA, Beyene M, Carelli RM, Wightman RM. Synaptic overflow of dopamine in the nucleus accumbens arises from neuronal activity in the ventral tegmental area. J Neurosci. 2009; 29:17351742. [PubMed: 19211880]

Svensson TH. Dysfunctional brain dopamine systems induced by psychotomimetic NMDA-receptor antagonists and the effects of antipsychotic drugs. Brain Res Brain Res Rev. 2000; 31:320-329. [PubMed: 10719159]

Thompson JL, Borgland SL. Presynaptic leptin action suppresses excitatory synaptic transmission onto ventral tegmental area dopamine neurons. Biol Psychiat. 2013; 73:860-868. [PubMed: 23305991]

Wanat MJ, Hopf FW, Stuber GD, Phillips PE, Bonci A. Corticotropin-releasing factor increases mouse ventral tegmental area dopamine neuron firing through a protein kinase $\mathrm{C}$-dependent enhancement of Ih. J Physiol. 2008; 586:2157-2170. [PubMed: 18308824]

Yavich L. Two simultaneously working storage pools of dopamine in mouse caudate and nucleus accumbens. Brit J Pharmacol. 1996; 119:869-876. [PubMed: 8922734]

Yavich L, MacDonald E. Dopamine release from pharmacologically distinct storage pools in rat striatum following stimulation at frequency of neuronal bursting. Brain Res. 2000; 870:73-79. [PubMed: 10869503]

Yorgason JT, Espana RA, Jones SR. Demon voltammetry and analysis software: analysis of cocaineinduced alterations in dopamine signaling using multiple kinetic measures. J Neurosci Meth. 2011; 202:158-164.

Zhang H, Sulzer D. Glutamate spillover in the striatum depresses dopaminergic transmission by activating group I metabotropic glutamate receptors. J Neurosci. 2003; 23:10585-10592. [PubMed: 14627643]

Zhang L, Doyon WM, Clark JJ, Phillips PE, Dani JA. Controls of tonic and phasic dopamine transmission in the dorsal and ventral striatum. Mol Pharmacol. 2009; 76:396-404. [PubMed: 19460877]

Zweifel LS, Argilli E, Bonci A, Palmiter RD. Role of NMDA receptors in dopamine neurons for plasticity and addictive behaviors. Neuron. 2008; 59:486-496. [PubMed: 18701073]

Zweifel LS, Parker JG, Lobb CJ, Rainwater A, Wall VZ, Fadok JP, Darvas M, Kim MJ, Mizumori SJ, Paladini CA, Phillips PE, Palmiter RD. Disruption of NMDAR-dependent burst firing by 
dopamine neurons provides selective assessment of phasic dopamine-dependent behavior. Proc Natl Acad Sci USA. 2009; 106:7281-7288. [PubMed: 19342487] 

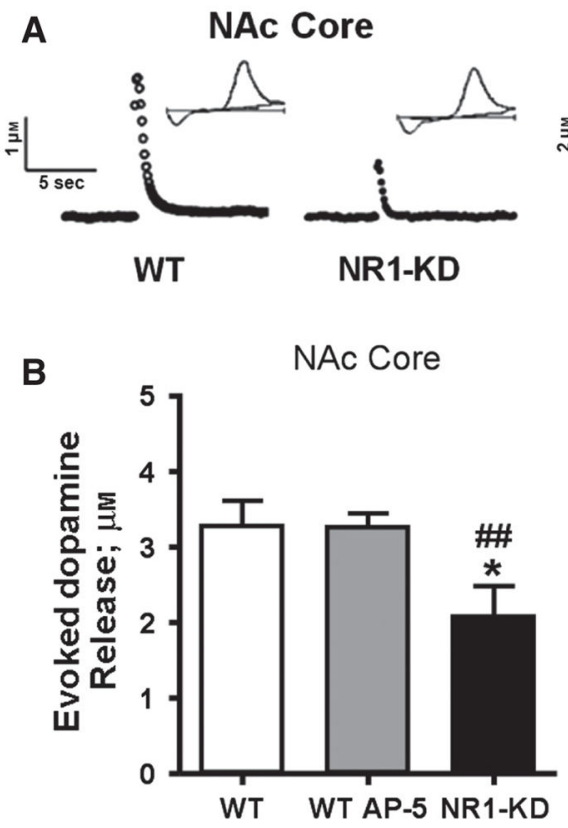

Caudate

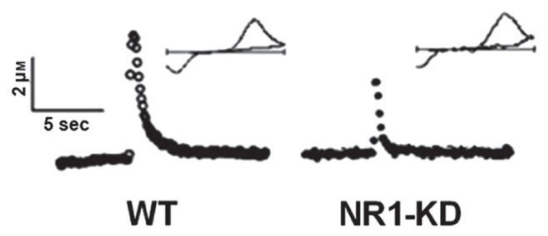

Caudate

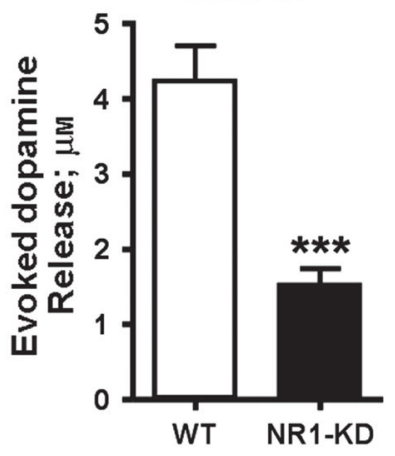

Fig. 1.

Reduced DA release in NR1-KD mice. (A) Representative traces of electrically-evoked DA overflow, measured by fast-scan cyclic voltammetry in brain slices of WT and NR1-KD mice. (B) Grouped data of DA peak height measurements for the NAc core (left) and caudate (right), reflecting DA release. $* P<0.05, * * * P<0.001$ for WT and NR1-KD; \#\#P< 0.01 for WT AP-5 and NR1-KD. 
A

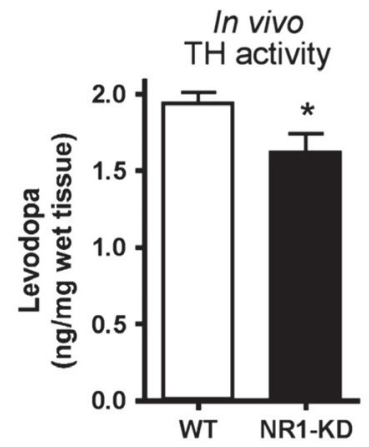

B
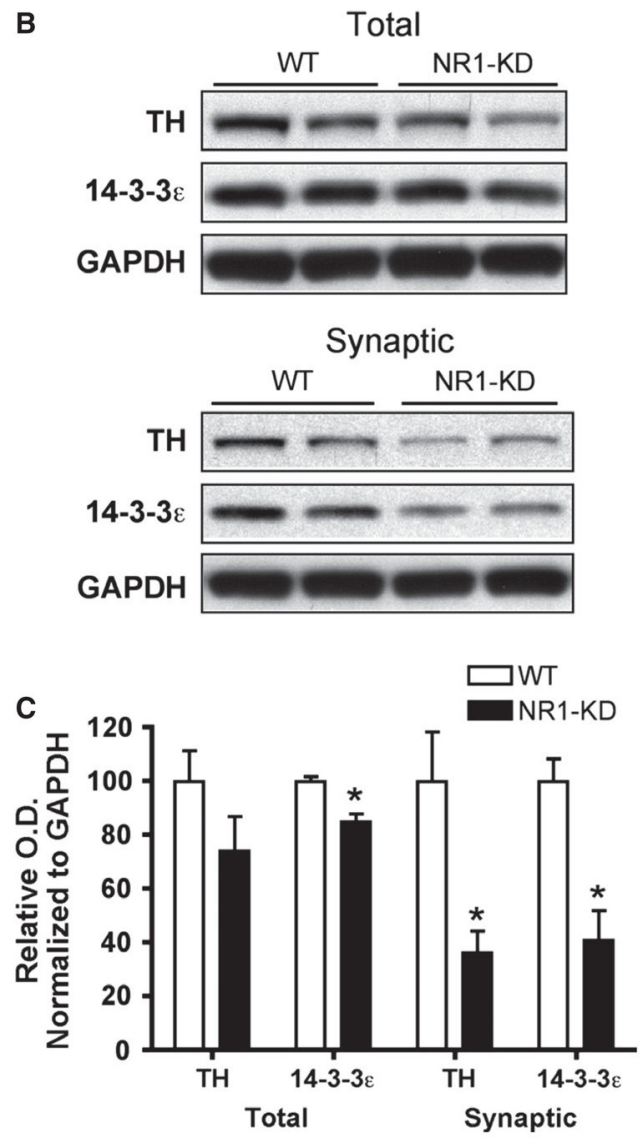

Fig. 2.

Reduction of TH activity and level in NR1-KD mice. (A) Accumulation of L-DOPA in striatal tissues after treatment with 3-hydroxybenzylhydrazine, reflecting accumulation of the product of in vivo TH activity. (B) Western blot of striatal protein extracts (total protein and synaptic fractions) from WT and NR1-KD mice, immunoblotted for TH protein, 14-3-3e, and GAPDH as a loading control. (C) Densitometry of the O.D. of TH and 14-3-3e levels present in total and synaptic fractions, normalized to GAPDH. $n=6$ per genotype, ${ }^{*} P$ $<0.05$. GAPDH, glyceradehyde 3-phosphate dehydrogenase; O.D., optical density. 
A
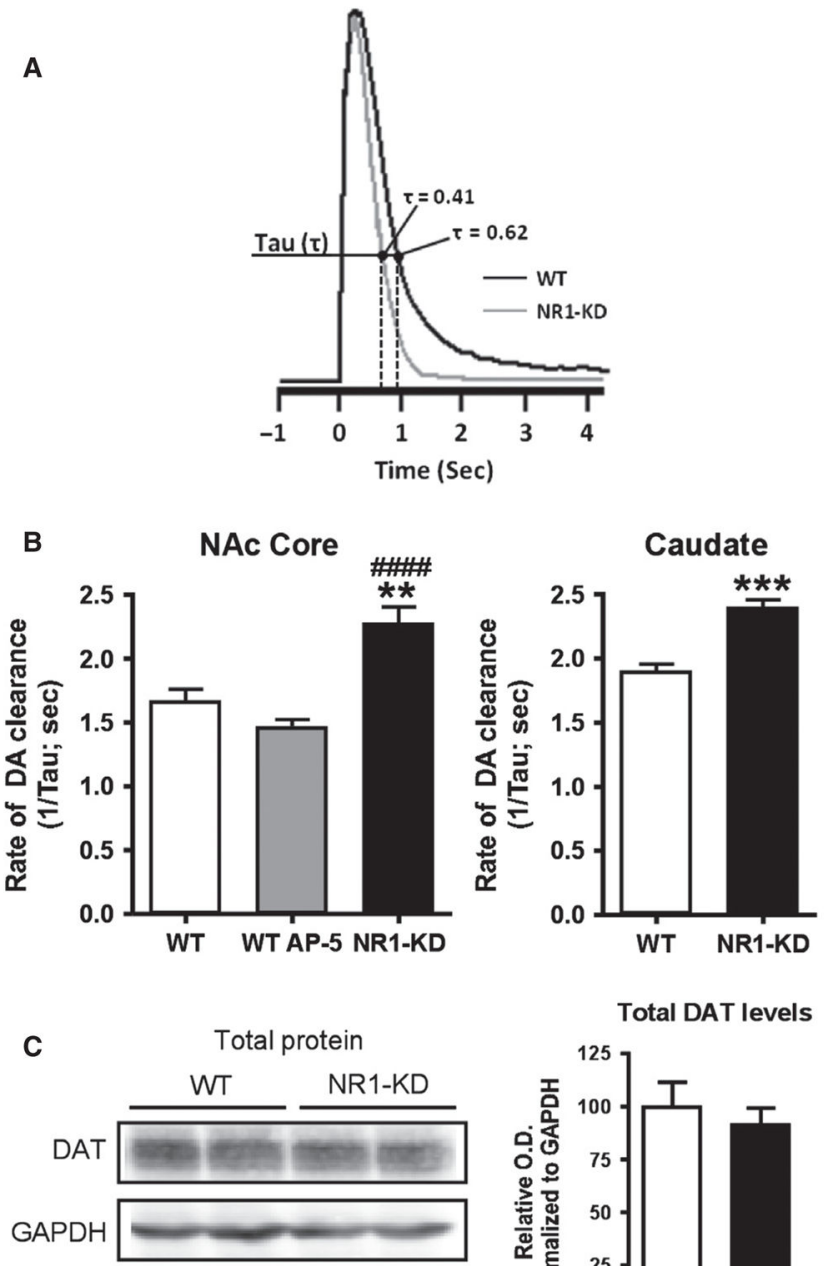

Total DAT levels
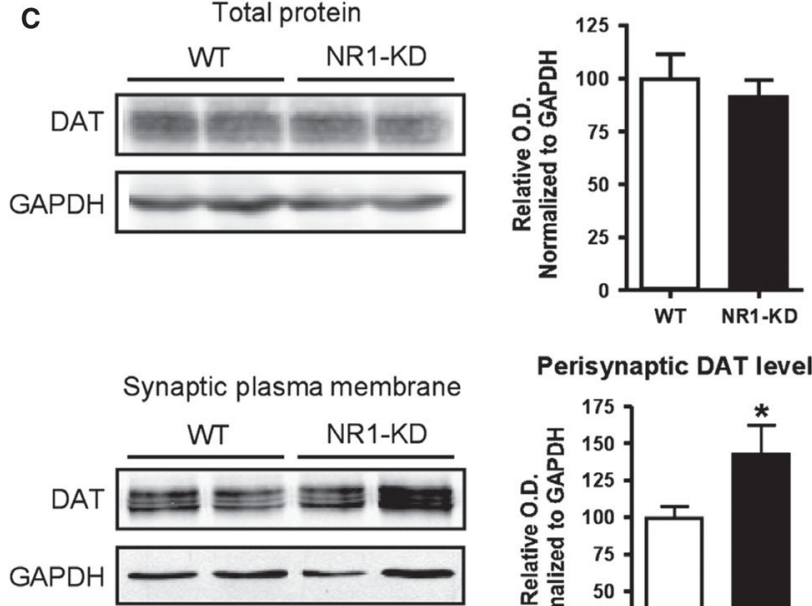

$$
\text { Perisynaptic DAT levels }
$$

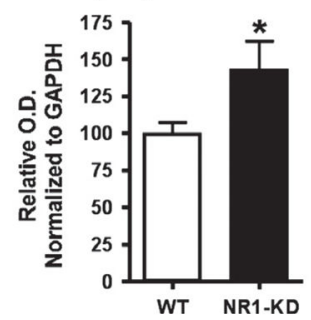

Fig. 3.

Increased DAT activity and protein levels, and increased DA clearance rate and synaptic DAT levels in NR1-KD mice. (A) Representative trace of DA efflux from WT (black line) and NR1-KD (gray line) brain slices (normalized peak height), demonstrating the time constant, tau, which is the time required (in s) for the decaying signal to reach one-third of the peak height. (B) DA clearance is more rapid in the NAc core and CPu brain slices from NR1-KD mice, but is unaffected by the presence of AP-5. DA clearance is represented as $1 /$ tau to demonstrate that a smaller tau value indicates a more rapid clearance. (C) Western 
blot of total and synaptic protein fractions from WT and NR1-KD striatum, immunoblotted for the DAT and GAPDH as a loading control. Bar graph depicts densitometry of DAT normalized to GAPDH based on their relative O.D. $n=6$ per genotype, ${ }^{*} P<0.05$, ${ }^{* *} P<$ $0.01, * * * P<0.001$ for WT and NR1-KD; \#\#\#\#P<0.0001 for WT AP-5 and NR1-KD. GAPDH, glyceradehyde 3-phosphate dehydrogenase; O.D., optical density. 

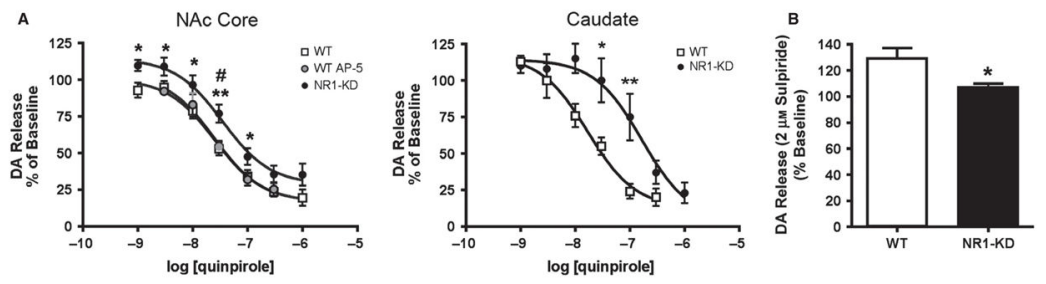

Fig. 4.

Reduced $\mathrm{D}_{2}$ autoreceptor regulation of DA release. (A) NR1-KD mice are less sensitive to the inhibitory effect of the $\mathrm{D}_{2}$ agonist quinpirole on DA signals in the NAc core and $\mathrm{CPu}$. The effect of quinpirole is unchanged in the presence of AP-5. (B) NR1-KD mice are also less sensitive to the disinhibitory effect of the $\mathrm{D}_{2}$ antagonist sulpiride on DA signals in the $\mathrm{CPu} . n=6$ per genotype, $* P<0.05$, $* * P<0.01$ for $\mathrm{WT}$ and NR1-KD; $\# P<0.05$ for WT AP-5 and NR1-KD. 
A

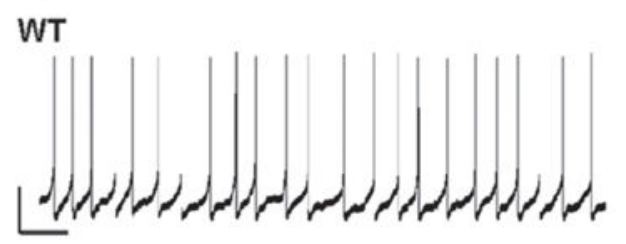

NR1-KD

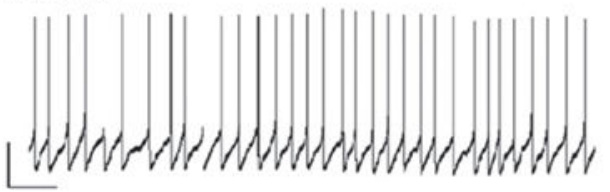

B

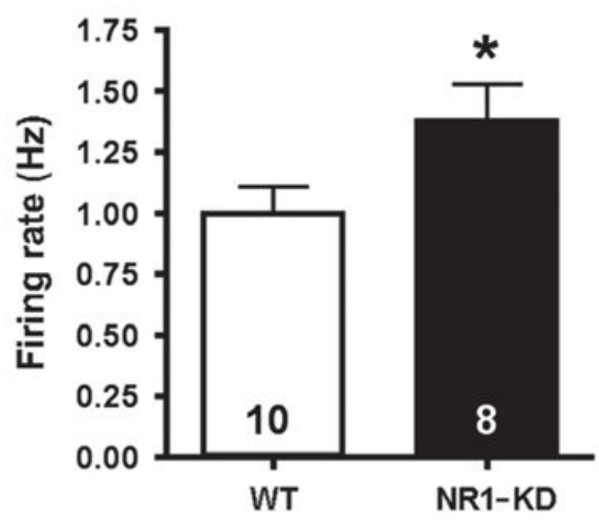

C

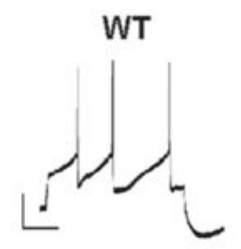

NR1-KD

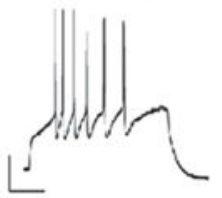

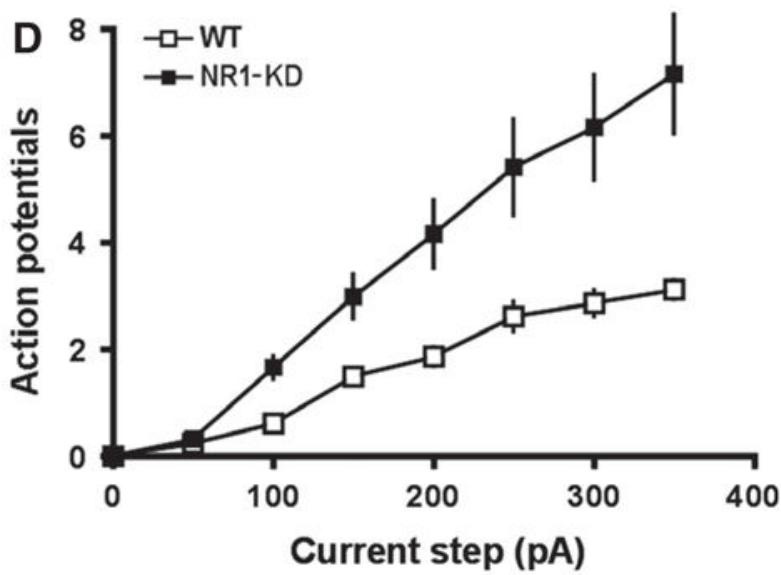

Fig. 5.

Increased tonic firing rate and excitability of VTA neurons. (A) Representative traces of current-clamp recordings of basal firing rates from VTA neurons from WT mice or NR1-KD mice. Scale bars: $20 \mathrm{mV}, 2$ s. (B) Basal firing rate was significantly greater in VTA neurons of NR1-KD mice ( $n=8$ cells from four mice) compared with WT mice $(n=10$ cells from four mice, $* P<0.05)$. (C) Example recordings of VTA neurons from WT mice or NR1-KD mice show firing at a depolarizing step to $+250 \mathrm{mV}$ elicited when neurons were held at -60 $\mathrm{mV}$. Scale bars: $20 \mathrm{mV}, 100 \mathrm{~ms}$. (D) Excitability was measured by determining the slope of the line given by number of spikes fired at each depolarizing step. Neurons from the VTA of NR1-KD mice ( $n=12$ cells from four mice) had a significantly greater slope compared with VTA neurons from WT mice $(n=8$ cells from four mice, $* P<0.05)$. VTA, ventral tegmental area. 
A
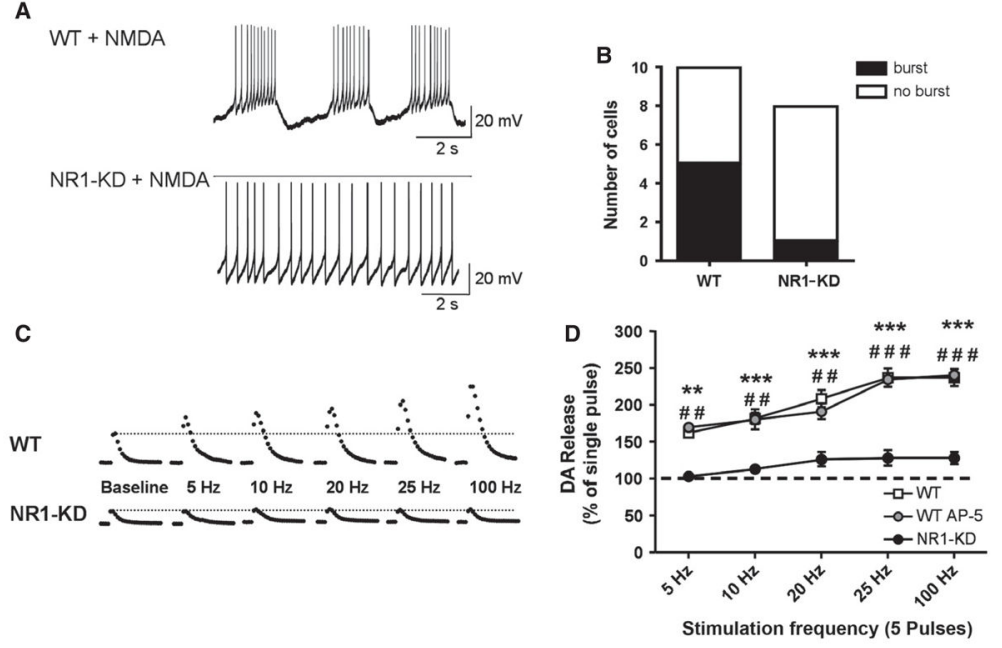

Fig. 6.

Reduced burst firing and impaired ability to generate DA overflow. (A) Representative trace of burst firing pattern from WT and NR1-KD VTA neurons. (B) Proportion of recorded VTA neurons that exhibited burst firing during slice recordings. (C) Inability of stimulations representing phasic bursting of DA neurons to augment DA overflow in NR1-KD mice.

Representative DA efflux traces from the CPu of WT and NR1-KD brain slices. Five-pulse stimulation, at frequencies ranging from 5 to $100 \mathrm{~Hz}$, causes an augmentation of DA overflow over what is elicited by a single-pulse stimulation (baseline, dotted line) in WT but not NR1-KD mice. DA overflow was not affected by the presence of $50 \mu \mathrm{M}$ AP-5. (D) Group data depicting robust increases in DA release as frequency increases in WT slices and in WT slices in the presence of AP-5, but not in NR1-KD slices. The amount of DA overflow is expressed as a percentage of the baseline (single pulse) at five pulse trains of 5$100 \mathrm{~Hz}$. $* * P<0.01, * * * P<0.001$ for WT and NR1-KD; \#\#P<0.01, \#\#\#P<0.001 for WT AP-5 and NR1-KD. VTA, ventral tegmental area. 